07

\title{
Синхронизация колебаний наногенератора внешним источником
}

\author{
(c) К.Н. Алешин, В.В. Матросов, К.Г. Мишагин
}

Нижегородский государственный университет им. Н.И. Лобачевского, Нижний Новгород

E-mail: kirill_al@bk.ru

Поступило в Редакцию 28 сентября 2016 г.

Рассматривается динамика спинового наногенератора вида „точечный контакт“ при воздействии на него спиновой волны, возбуждаемой внутри ферромагнитного слоя внешним источником. Показано, что колебания наногенератора могут быть синхронизированы внешним источником, в пространстве параметров выделены области захвата и удержания режима синхронизации. Представлены зависимости амплитуды спиновой волны от параметров внешнего воздействия.

DOI: $10.21883 /$ PJTF.2017.06.44398.16507

Необходимость миниатюризации и повышения производительности вычислительных устройств заставляет искать новые инженерные решения для удовлетворения нужд современной промышленности. Одним из перспективных направлений является спинтроника, которая использует тонкие слоеные структуры из материалов с различными магнитными свойствами. В частности, на основе подобных структур реализуются спиновые наногенераторы. Такие проблемы спиновых наногенераторов, как малая мощность генерируемого СВЧ-сигнала и высокий уровень фазовых шумов, делают актуальной задачу синхронизации нескольких наногенераторов. В данной работе представлены результаты исследования особенностей синхронизации колебаний наногенератора спиновой волной, возбуждаемой сторонним источником в ферромагнитном слое спинового наногенератора. Изучаются зависимости величин полосы захвата и полосы удержания, а также амплитуды спиновой волны, возбуждаемой наногенератором, от параметров внешнего воздействия.

Спиновый наногенератор представляет собой многослойную структуру, состоящую из чередующихся ферромагнитных слоев и прово- 
дящих электрический ток немагнитных слоев, подобную структуру также называют спиновым вентилем. Источником энергии для возбуждения автоколебаний является электрический ток, протекающий через структуру, а диссипация обусловлена в основном взаимодействием электронов с кристаллической решеткой, вихревыми токами и магнонмагнонным взаимодействием. Динамика наногенератора определяется поведением магнитного момента одного из ферромагнитных слоев, называемого свободным слоем. Возможность автоколебаний в таких системах была предсказана теоретически [1], а затем подтверждена численными и натурными экспериментами [2]. В режиме автоколебаний магнитный момент свободного слоя прецессирует вокруг направления эффективного магнитного поля [3]. В данной работе предполагается топология спинового наногенератора вида „точечный контакт“ [2], при которой его структура должна рассматриваться как пространственнораспределенная. В режиме автоколебаний внутри свободного слоя наногенератора данного вида происходит возбуждение стоячей спиновой автоволны.

Отметим, что спиновая волна, воздействующая на наногенератор, может быть возбуждена с помощью наноразмерных антенн, создающих СВЧ-излучение вблизи свободного слоя [4].

Для понимания процессов синхронизации наногенератора спиновой волной, возбуждаемой сторонним источником в свободном слое, рассмотрим математическую модель, предложенную в работе [5]. Учитывая внешнее воздействие и замену переменных для комплексной амплитуды спиновой волны $c=\rho^{*} \exp \left(i \varphi_{c}\right)$, где $\rho^{*}$ - действительная амплитуда, а $\varphi_{c}$ - фаза спиновой волны, получим систему обыкновенных дифференциальных уравнений, описывающих модель наногенератора:

$$
\left\{\begin{array}{l}
\frac{d \rho}{d \tau}=-\rho\left(B_{2}+B_{3} \rho^{2}\right)-\lambda^{2} \rho_{1}^{2} \rho\left(B_{12} \sin \theta+B_{22} \cos \theta+B_{21}\right) \\
\frac{d \theta}{d \tau}=-2\left(\gamma+B_{1} \rho^{2}-C \rho_{1}^{2}\right)-2 \lambda^{2} \rho_{1}^{2}\left(-B_{22} \sin \theta+B_{21} \cos \theta+B_{11}\right)
\end{array}\right.
$$

где $\rho=\rho^{*} /(N S), N-$ количество частиц со спином $S$ в области точечного контакта наногенератора; $\tau=t \omega_{e}-$ безразмерное время; $\theta$ - мгновенная разность фаз колебаний наногенератора и внешнего воздействия; $\rho_{1}-$ амплитуда внешнего воздействия; $\gamma=\left(\omega_{c} / \omega_{e}-1\right)-$ начальная относительная частотная расстройка между $\omega_{c}-$ частотой колебаний наногенератора и $\omega_{e}$ - частотой внешнего воздей-

Письма в ЖТФ, 2017, том 43, вып. 6 


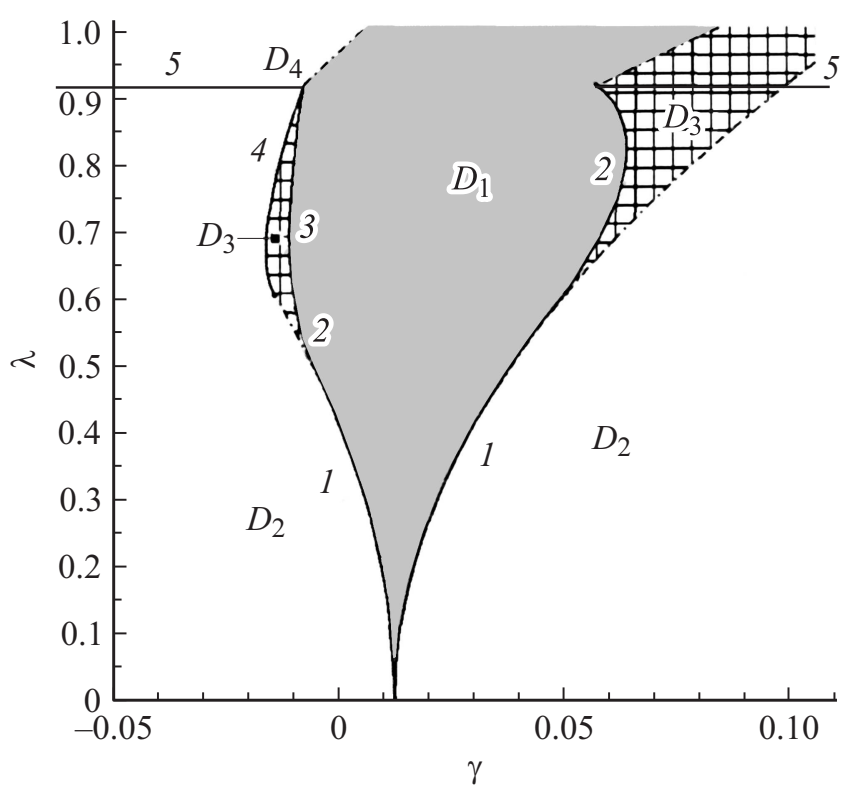

Рис. 1. Области захвата и удержания частоты спиновой волны наногенератора внешним источником.

ствия; $\lambda$ характеризует долю энергии внешнего возбуждения, попавшую в область точечного контакта наногенератора; параметры $B_{1}=-1.022, B_{2}=-0.0447, B_{3}=0.4983, B_{11}=-1.5636, B_{12}=0.4347$, $B_{21}=0.6757, B_{22}=0.2285$ и $C=-1.0147$ вычислены в силу физических параметров [6]. Диапазон изменения $\lambda-$ это интервал $(0,1)$, при этом нулевое значение соответствует бесконечно удаленному центру внешнего возбуждения, а значение $\lambda=1$ соответствует положению центра возбуждения внутри области точечного контакта спинового наногенератора. Значение $\rho_{1}$ выберем таким образом, чтобы амплитуда спиновой волны, возбуждаемой внешним источником, была равна амплитуде спиновой волны, возбуждаемой невозмущенным наногенератором, т.е. $\rho_{1}=0.2798$.

Модель (1) определена в цилиндрическом фазовом пространстве $U=\{\theta(\bmod 2 \pi), \rho\}$, анализ движений в котором свидетельствует о наличии трех видов аттракторов, которые и определяют основные 

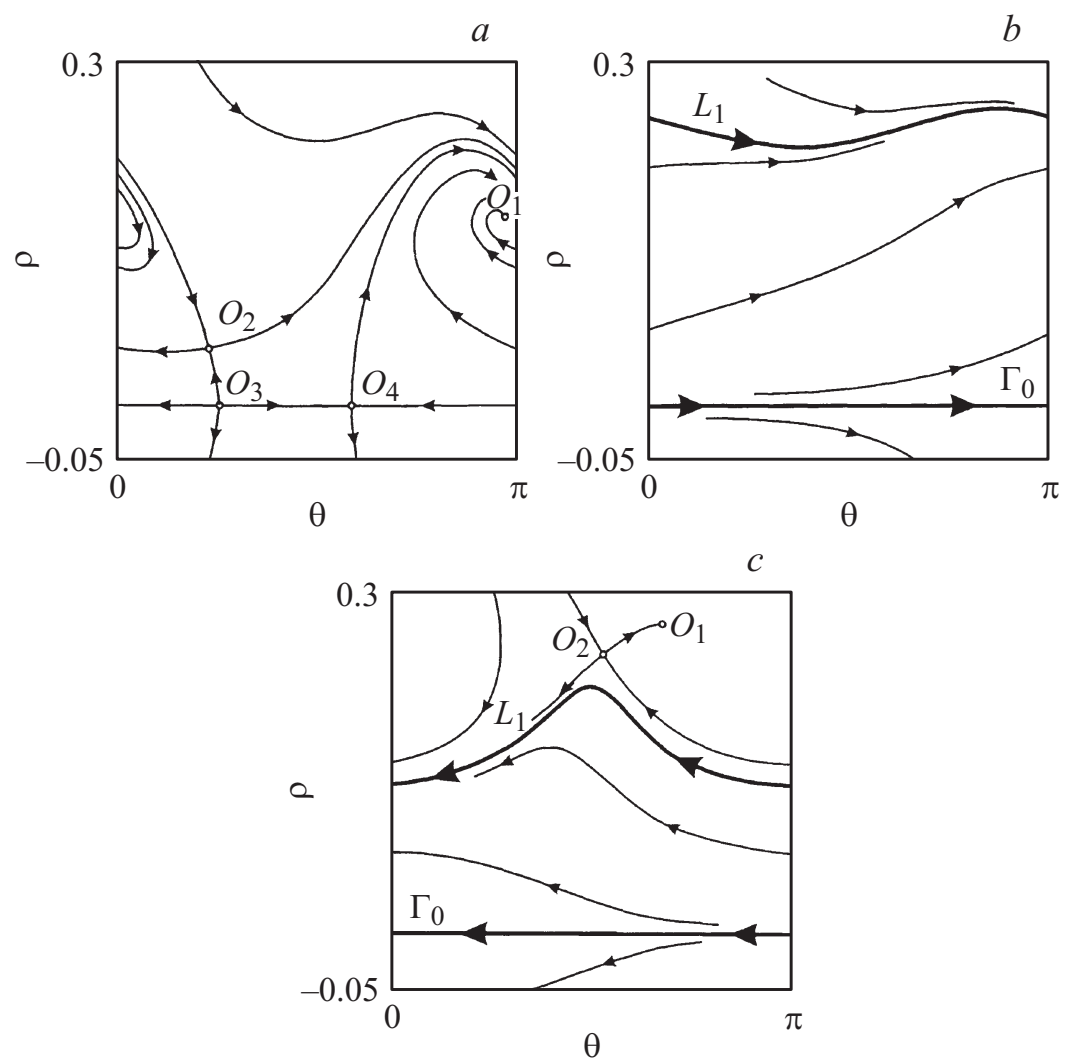

Рис. 2. Характерные фазовые портреты модели (1) при значениях параметров из областей $D_{1}(a), D_{2}(b), D_{3}(c)$.

динамические режимы и характеристики спинового наногенератора при воздействии внешнего источника. Далее остановимся на рассмотрении результатов моделирования системы (1), представленных параметрическим (рис. 1) и фазовыми портретами (рис. 2).

Образом синхронного режима в фазовом пространстве $U$ является устойчивое состояние равновесия $O_{1}\left(\theta^{1}, \rho^{1}\right)$ (рис. $\left.2, a, b\right)$, координата $\theta^{1}$ характеризует разность фаз колебаний наногенератора и внешнего сигнала в режиме синхронизации, $\rho^{1}-$ амплитуду спиновой волны.

Письма в ЖТФ, 2017, том 43, вып. 6 
C режимом синхронизации неразрывно связаны такие понятия, как полоса захвата и полоса удержания синхронного режима. Под полосой захвата понимается область начальных частотных расстроек генератора и внешнего сигнала, в которой при любых начальных условиях устанавливается режим синхронизации. Полоса удержания синхронного режима есть область начальных частотных расстроек, где синхронный режим существует. Для модели (1) полоса (область) захвата совпадает с областью глобальной устойчивости состояния равновесия $O_{1}$, а область удержания - с областью существования устойчивого состояния равновесия $O_{1}$. На рис. 1 область захвата $D_{1}$ выделена серым цветом, область удержания включает область захвата и области $D_{3}$, отмеченные штриховкой. Из анализа рис. 1 следует, что при усилении внешнего воздействия полоса захвата увеличивается, достигает своего максимума при $\lambda=0.8$, далее сужается, но при прохождении через значение $\lambda=0.91917$ вновь расширяется, смещаясь в область положительных частотных расстроек $\gamma$. Полоса удержания с ростом $\lambda$ расширяется.

Вне полосы удержания генератор переходит в режим биений, в котором разность частот колебаний наногенератора и внешнего воздействия, а также амплитуда спиновой волны периодически меняются около некоторого среднего значения. Образом режима биений в фазовом пространстве $U$ является устойчивый предельный цикл $L_{1}$ с ненулевой амплитудой $\rho_{L 1}(t) \neq 0$ (рис. $\left.2, b, c\right)$. В областях, отмеченных штриховкой, цикл $L_{1}$ существует совместно с устойчивым состоянием равновесия $O_{1}$ (рис. 2,b), здесь система демонстрирует бистабильное поведение. В области $D_{4}$ единственным аттрактором модели является устойчивый предельный цикл, для которого $\rho(t)=0$. При значениях из этой области автоколебания спинового генератора отсутствуют.

На рис. 1 границы выделенных областей определяют следующие бифуркационные кривые: двукратного состояния равновесия (штрихпунктирные линии), петли сепаратрис седло-узла (линии 1), петли сепаратрис седла $\mathrm{O}_{2}$ (линии 2), двукратного предельного цикла (линия 3), бифуркации Андронова-Хопфа с положительной первой ляпуновской величиной (линия 4), бифуркации трехкратного предельного цикла (линия 5).

На рис. 3 приведены зависимости амплитуды спиновой волны, генерируемой в области точечного контакта, от параметров внешнего воздействия в синхронном режиме и режиме биений. Здесь штрих-

Письма в ЖТФ, 2017, том 43, вып. 6 


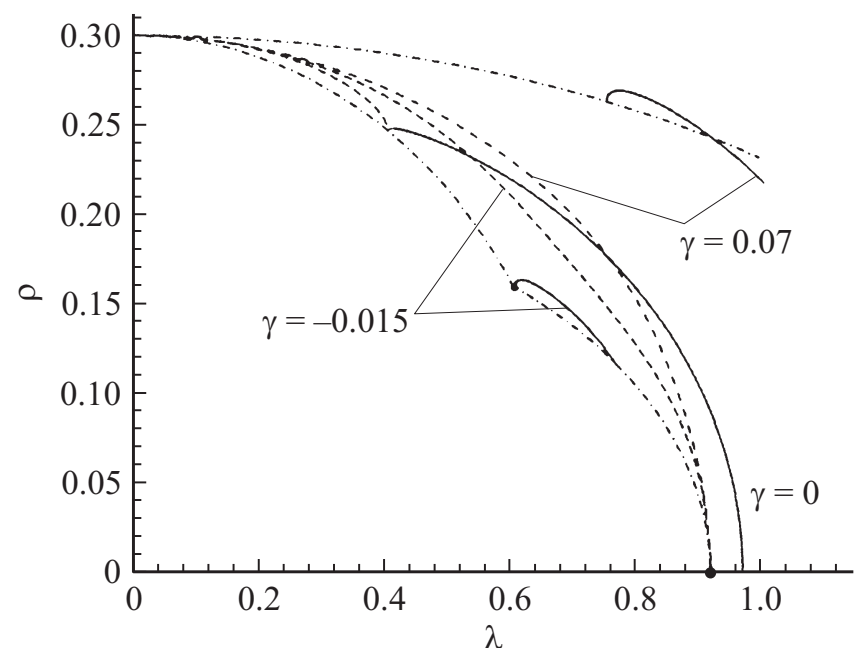

Рис. 3. Зависимость амплитуды спиновой волны наногенератора от параметров внешнего воздействия.

пунктирные линии ограничивают область существования синхронного режима. Сплошные линии отражают эволюцию координаты $\rho^{1}$ при изменении параметра $\lambda$, пунктирные линии представляют изменение величины $\rho_{L 1}$, усредненной на периоде цикла амплитуды режима биений. Из представленных диаграмм следует, что при приближении центра внешнего возбуждения к наногенератору амплитуда колебаний автогенератора убывает как в синхронном режиме, так и в режиме биений. В зонах бистабильного поведения амплитуда спиновой волны в синхронном режиме больше усредненной амплитуды волны в режиме биений при положительных частотных расстройках и ниже при $\gamma<0$.

В рамках этой работы для теоретической модели спинового наногенератора, находящегося под внешним воздействием в виде спиновой волны, в пространстве параметров выделены области захвата и удержания режима синхронизации, изучено поведение на границах выделенных областей. Показано, что приближение внешнего возбуждения к центру точечного контакта вне области синхронизации приводит к подавлению автоколебаний спинового генератора. Полученные результаты могут быть использованы при исследовании взаимной синхронизации спи-

Письма в ЖТФ, 2017, том 43, вып. 6 
новых наногенераторов для когерентного сложения их мощностей и подавления фазовых шумов результирующего сигнала.

Отметим, что гистерезис, обнаруженный при синхронизации внешней спиновой волной, также проявляется и при других способах синхронизации [7,8]. Данное явление обнаружено экспериментально [9] и может быть также объяснено с помощью макроспиновой модели на основе уравнения Ландау-Лифшица с дополнительным слагаемым Слончевского. Качественно явление гистерезиса можно связать со свойством неизохронности колебаний спинового генератора [9].

Работа поддержана грантом № 3.820.2014/К Министерства образования и науки РФ.

\section{Список литературы}

[1] Slonczewski J.C. // J. Magn. Magn. Mater. 1996. V. 159. N 1. S. L1-L7.

[2] Silva T.J., Rippard W.H. // J. Magn. Magn. Mater. 2008. V. 320. N 7. P. 1260 1271.

[3] Мишагин К.Г., Алешин К.Н. // Вестник ННГУ. 2011. № 5(3). С. 270-273.

[4] Ciubotaru F. Spin-wave excitation by nano-sized antennas: Dissertation. Technische Universität Kaiserslautern, 2012.

[5] Rezende S.M., De Aguiar F.M., Azevedo A. // Phys. Rev. B. 2006. V. 73. N 9. P. 094402.

[6] Krivorotov I.N. et al. // Science. 2005. V. 307. N 5707. P. 228-231.

[7] Мишагин К.Г., Шалфеев В.Д. // Письма в ЖТФ. 2010. Т. 36. В. 22. С. 51-57.

[8] Митрофанов А.А., Сафин А.Р., Удалов Н.Н. // Письма в ЖТФ. 2014. Т. 40. B. 13. C. $66-72$.

[9] Tabor P. et al. // Phys. Rev. B. 2010. V. 82. N 2. P. 020407. 